Supplement of Atmos. Chem. Phys. Discuss., 15, 30895-30957, 2015

http://www.atmos-chem-phys-discuss.net/15/30895/2015/

doi:10.5194/acpd-15-30895-2015-supplement

(C) Author(s) 2015. CC Attribution 3.0 License.

(c) (i)

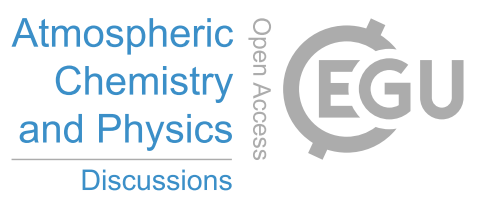

Supplement of

\title{
Atmospheric methane evolution the last 40 years
}

\section{S. B. Dalsøren et al.}

Correspondence to: S. B. Dalsøren (stigbd@ cicero.oslo.no)

The copyright of individual parts of the supplement might differ from the CC-BY 3.0 licence. 


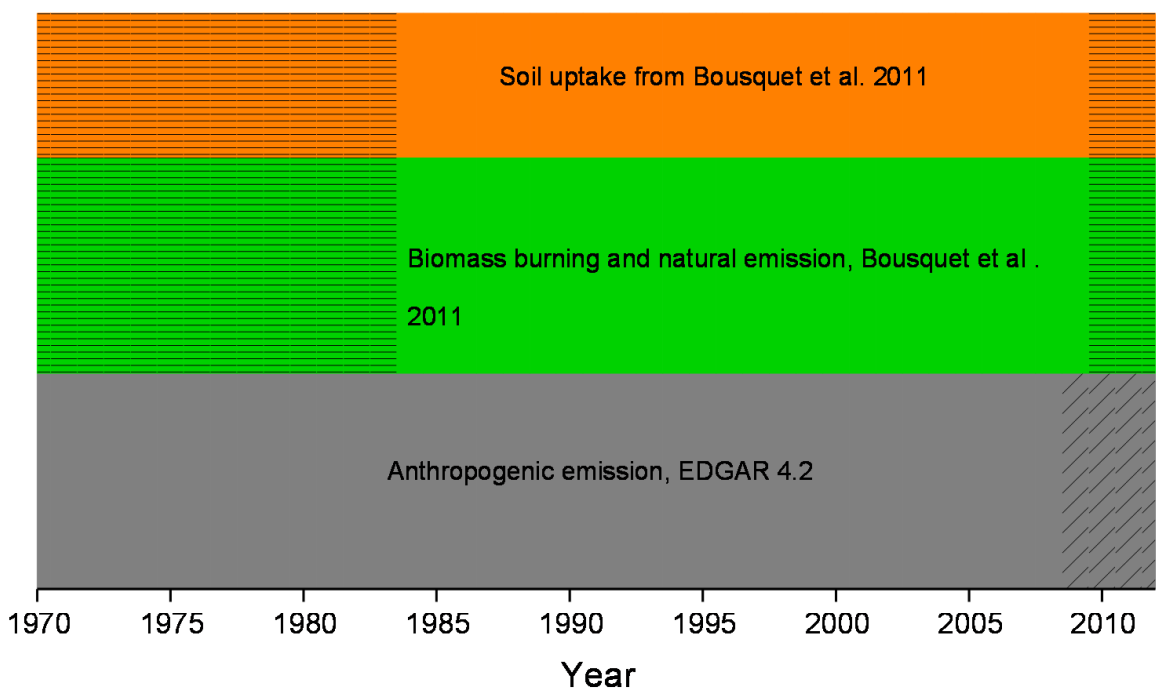

Soil uptake kept constant to first and last year of Bousquet et al. 2011

Biomass burning and natural emissions kept constant to first and last year of Bousquet et al. 2011 Extrapolation of the increase in EDGAR 4.2 anthropogenic emissions from 2007-2008

4 Figure S1. Overview of how emission inventories are included in the model for different time 5 periods.

6

$7 \quad$ S2 Emission sectors and tracers

8 Table S1. List of $\mathrm{CH}_{4}$ emission sectors and emission tracers used in the model simulations.

9 The text colours in column 1 and 2 shows the legend colours in Fig. 1 and Fig. 6-9.

\begin{tabular}{|l|l|l|}
\hline Wetlands & Emissions shown in Fig. 1 & $\begin{array}{l}\text { Tracer from these sectors shown in Fig. 6-9, } \\
\text { 11-13, named "Natural" }\end{array}$ \\
\cline { 1 - 2 } Biomass burning & Emissions shown in Fig. 1 & \multicolumn{1}{|l}{} \\
\cline { 1 - 2 } Oceans+Termites+other natural & Emissions shown in Fig. 1 & $\begin{array}{l}\text { Tracer from this sector shown in Fig. 6-9, 11- } \\
13\end{array}$ \\
\hline Enteric fermentation & Emissions shown in Fig. 1 \\
Agricultural soils & Emissions shown in Fig. 1 & $\begin{array}{l}\text { Tracer from this sector shown in Fig. 6-9, 11- } \\
13\end{array}$ \\
\hline Solid fuels: Fugitive from solids & Emissions shown in Fig. 1 & $\begin{array}{l}\text { Tracer from this sector shown in Fig. 6-9, 11- } \\
13\end{array}$ \\
\hline Gas production and distribution & Emissions shown in Fig. 1 & $\begin{array}{l}\text { Tracer from this sector shown in Fig. 6-9, 11- } \\
13\end{array}$ \\
\hline Sum all other anthropogenic (those listed below) & Emissions shown in Fig. 1 & $\begin{array}{l}\text { Tracer from this sector shown in Fig. 6-9, 11- } \\
13\end{array}$ \\
\hline Solid waste & & \\
\hline Waste water & & \\
\hline Residential & & \\
\hline Manure management & & \\
\hline Energy manufacturing transformation & & \\
\hline
\end{tabular}




\begin{tabular}{|l|l|l|}
\hline Agricultural waste burning & & \\
\hline Road transportation & & \\
\hline Fossil fuel fires & & \\
\hline Non-road transportation & & \\
\hline Oil production and refineries & & \\
\hline Industrial process and product use & & \\
\hline
\end{tabular}

1

\section{S3 Theoretical foundation of the use of the fictitious tracers}

As indicated in Sect. 2.2 of the main paper, the simulations used 18 passive fictitious tracers for each of the $\mathrm{CH}_{4}$ emission sectors listed in Table S1. The tracers were continuously emitted and then given an e-folding lifetime of 1 month undergoing transport but not interacting chemically. These tracers were used as a proxy for the different sector's recent contribution to monthly mean surface $\mathrm{CH}_{4}$ concentrations, with the aim of revealing key sectors and regions behind recent changes in spatial distribution or temporal evolution of $\mathrm{CH}_{4}$. In this section, we provide the theoretical foundation that justifies the use of these fictitious tracers.

Firstly, we summarize the results obtained in this section. We split the $\mathrm{CH}_{4}$ mole fraction into two components: a quite uniform background component $\left(\mathrm{r}_{\mathrm{B}}\right)$ and an inhomogeneous recently emitted component $\left(\mathrm{r}_{\mathrm{R}}\right)$; being the fictitious tracer a proxy for the second component. The $\mathrm{CH}_{4}$ surface emissions act as the sources for $\mathrm{r}_{\mathrm{R}}$ (not for $\mathrm{rB}$ ), then this component is advected and mixed, and when achieving a good mixing (after 1-2 months) it is converted into $\mathrm{r}_{\mathrm{B}}$. Since the life time of $\mathrm{rR}_{\mathrm{R}}$ is of around 1 month (much smaller than the mean $\mathrm{CH}_{4}$ lifetime), the chemical destruction acting on $\mathrm{r}_{\mathrm{R}}$ is almost negligible (only acts on $\mathrm{r}_{\mathrm{B}}$ ). The same reason makes $\left|\mathrm{r}_{\mathrm{B}}\right|>>\left|\mathrm{r}_{\mathrm{R}}\right|$, except very near strong $\mathrm{CH}_{4}$ emission sources.

We start with the continuity equation for the $\mathrm{CH}_{4}$ mole fraction (r) in dry air:

$\frac{D r}{D t}=-\frac{1}{n} \nabla \cdot \vec{F}_{D}(r)-\sum_{i} k_{i} \cdot c_{i} \cdot r$

where $\mathrm{D} / \mathrm{Dt}$ is the Lagrangian time derivate, $\mathrm{n}$ is the number density $\left(\mathrm{mol} / \mathrm{m}^{3}\right)$ of the dry air, the vector $F_{D}$ is the diffusive flux due to turbulence (i.e., unresolved flow by the spatial scale of the model), $\mathrm{k}_{\mathrm{i}}$ is the reaction rate with the trace gas $\mathrm{i}$ and $\mathrm{c}_{\mathrm{i}}$ is the number density of the trace gas i. Note that the diffusive flux is linear in r (e.g., proportional to the gradient of r), even in the case in which the flux is non local (e.g., see Holtslag \& Boville, 1993), as well as the rest of the terms of Eq. (1). The surface sources and sinks enter as the boundary conditions of Equation (1). 
2 Now, we split Eq. (1) into two equations (this is our definition for the components $\mathrm{r}_{\mathrm{B}}$ and $\mathrm{r}$;

3 we do not base our definition in spatial averages):

$4 \quad \frac{D r_{B}}{D t}=-\frac{1}{n} \nabla \cdot \vec{F}_{D}\left(r_{B}\right)-\sum_{i} k_{i} \cdot c_{i} \cdot r_{B}+P\left(r_{R}\right)$

$5 \quad \frac{D r_{R}}{D t}=-\frac{1}{n} \nabla \cdot \vec{F}_{D}\left(r_{R}\right)-\sum_{i} k_{i} \cdot c_{i} \cdot r_{R}-P\left(r_{R}\right)$

6 where the chemical losses in Eq. (3) will be almost negligible except very near strong $\mathrm{CH}_{4}$

7 sources (as explained in the second paragraph of this section), and $\mathrm{P}$ is a linear projector onto

8 a complete set of vectors (spectral components) for wavelengths larger than around 6,000 km.

9 This projector continuously removes the smoothed part of $r_{R}$, which is continuously created as

10 the emitted $\mathrm{CH}_{4}$ becomes well mixed, and converts it into $\mathrm{r}_{\mathrm{B}}$. The $\mathrm{CH}_{4}$ surface emissions are

11 only included as boundary conditions for Eq. (3) (not for Eq. (2)). The $\mathrm{CH}_{4}$ surface sink is

12 only included as boundary condition for Eq. (2). Note that summing Eqs. (2) and (3), Eq. (1) is obtained. The reason for chosen $6,000 \mathrm{~km}$ as threshold wavelength is: 1) The mid-latitude synoptic scale motions have a characteristic variation length, L, of around 1,000 km (e.g., see Holton, 1992), and their associated wavelength is therefore of around 6,000 km. 2) Synoptic scale latitudinal motions are able to build up mole fraction inhomogeneities by advection of the $\mathrm{CH}_{4}$ climatological latitudinal pattern. 3) What makes more sense is to convert $\mathrm{r}_{\mathrm{R}}$ into $\mathrm{r}_{\mathrm{B}}$ around the smaller scale in which the background by itself can build up inhomogeneities. Anyway, in the main article we plot and analyse monthly averages, therefore the mole fraction mark due to synoptic motions will be smoothed.

In the main paper, instead of using the no local projector operator for coupling $r_{R}$ and $r_{B}$, we use a simpler local proxy for this purpose: a volumetric sink for $\mathrm{r}_{\mathrm{R}}$ with an e-folding lifetime of 1 month $\left(\mathrm{A} \times \mathrm{r}_{\mathrm{R}}\right.$ instead of $\mathrm{P}\left(\mathrm{r}_{\mathrm{R}}\right)$, with $\mathrm{A}=1$ month $\left.^{-1}\right)$. This process can approximately mimic the projector behaviour: it transforms $r_{R}$ into $r_{B}$ at a rate similar to that in which the projector acts (i.e., the rate at which mixing is able to smooth the emitted $\mathrm{CH}_{4}$ till the 1,000 $\mathrm{km}$ characteristic variation length at which the projector starts to act). Indeed, $\mathrm{r}_{\mathrm{R}}$ will be underestimated a bit because part of it will be removed by the 1-month lifetime e-folding sink before being smoothed to the $1,000 \mathrm{~km}$ characteristic variation length. The time needed to mix a species throughout a hemisphere is about 1 to 2 months, whereas 1 to 2 years are needed to mix a species through the entire Earth troposphere (Seinfeld \& Pandis, 1998). 
1 Now, we introduce the following notation: (Eulerian) annual means are denoted as $<>$ (in the

main paper we use annual running means since we are interested in the inter-annual variation of $\mathrm{CH}_{4}$ ), whereas longitudinal means along a whole terrestrial parallel are denoted as [ ]. Each variable can be decomposed in two components: the mean and the deviation from the average, for instance:

$r=<r>+r^{\prime}$

$r=[r]+r^{*}$

$<r\rangle=[<r\rangle]+\langle r\rangle^{*}$

We have found (see the main paper) that there is a high correlation between $\left\langle\mathrm{r}>*\right.$ and $\left\langle\mathrm{r}_{\mathrm{R}}\right\rangle^{*}$ for most of the stations, with $\mathrm{r}_{\mathrm{R}}$ defined using the local 1-month e-folding sink. Writing Eqs. (1) and (3) in conservative form, and expanding each variable simultaneously into its longitudinal and time components, in a similar fashion than Sect. 4.1.1 of Peixoto and Oort (1992), we have obtained quite complex PDEs (Partial differential Equations) linear in $<\mathrm{r}>*$ and $<_{\mathrm{R}}>^{*}$, respectively. Both equations are very similar (it is out of the scope of this paper to present such equations), and the main differences are:

a) a term containing the flux $[<\mathrm{r}\rangle]<\mathbf{v}>*$ appears in the first equation, whereas $\left.\left[<\mathrm{r}_{\mathrm{R}}\right\rangle\right]$ $<\mathbf{v}>*$ appears in the second equation (they are no homogeneous terms of the corresponding PDEs).

b) a chemical term containing $<\mathrm{k}_{\mathrm{i}} \mathrm{c}_{\mathrm{i}}>*\left[<\mathrm{r}_{\mathrm{B}}>\right]$ appears in the first equation, whereas the term $-\mathrm{A} \mathrm{n}<\mathrm{r}_{\mathrm{R}}>*$ appears in the second equation.

We expect these terms are usually small (because we expect $\left\langle\mathbf{v}>*\right.$ and $\left\langle\mathrm{k}_{\mathrm{i}} \mathrm{c}_{\mathrm{i}}\right\rangle^{*}$ are usually small; these are the prerequisites mentioned in the main paper), except the term $-\mathrm{A} n<\mathrm{r}_{\mathrm{R}}>*$ that we think it is compensated in the other PDE by a larger mixing (due to differential advection and turbulent diffusion), which tends to convert $<\mathrm{r}>*$ into $[<\mathrm{r}>*$ ] If both PDEs were identical, there would be a linear relation between their solutions, and the time linear correlation coefficient between the solutions would be exactly 1 . However, the few small differences between both PDEs make the time correlation coefficient between the solutions smaller than one. Note that $<\mathrm{r}>*$ changes along the corresponding parallel. For locations with $|<\mathrm{r}>*|$ small (i.e., $<\mathrm{r}>$ closes to $[<\mathrm{r}>]$ ) compared to the maximum and minimum within the parallel, the relative contribution of the terms different (between the PDEs) may be larger and therefore the correlation coefficient smaller for these locations (this might explain the case of the Wendover station). As mentioned in the previous paragraph, $\mathrm{r}_{\mathrm{R}}$ will be underestimated a 
1 bit when using the 1-month e-folding sink term, and this fact can contribute to the offset

2 between $\left\langle\mathrm{r}>* \text { and }<\mathrm{r}_{\mathrm{R}}\right\rangle^{*}$, and might explain why for most of the stations $|<\mathrm{r}>*|>\left|<\mathrm{r}_{\mathrm{R}}>*\right|$.

$4 \quad$ S4 Scaling procedure

5 As noted in the main text the model in general underestimates the observed surface methane

6 levels and likely reasons are discussed there. In Fig. 6-9 in the main article, the model results

7 are scaled to the observed mean over the periods of measurements to better discern

8 differences in trends between observations and model. To do this the absolute difference

9 between the model output and the measurements is calculated for each year in the period

10 1970-2012. The mean of these differences is then added to the modelled values for all years.

11 The model values are sampled from the gridbox with the closest location to the geographical

12 position of the stations. Likewise, the model layer best corresponding to the station altitude is used.

\section{S5 Discussion of sensitivity studies}

\section{S5.1 Influence of inter-annual variation in emissions from vegetation}

In the "main" simulation discussed in the main article, natural emission data for 2000 were used for all years and all components except $\mathrm{CH}_{4}$. The emissions from vegetation of $\mathrm{CO}$ and NMVOCs are from MEGAN (Guenther et al., 2006). Recently a new dataset (Sindelarova et al., 2014) with MEGAN emissions covering the period 1980-2010 became available. This dataset was used in the "bio" simulation to investigate whether inter-annual variations in CO and NMVOCs emissions from vegetation are important for the $\mathrm{CH}_{4}$ evolution. Variations in these emissions affect $\mathrm{OH}$ levels which in turn influence the atmospheric $\mathrm{CH}_{4}$ loss. Fig. S2 shows that surface $\mathrm{CH}_{4}$ levels are higher in the "bio" simulation. Due to the long response time of $\mathrm{CH}_{4}$ the difference between the two simulations grows over the first two decades. The higher $\mathrm{CH}_{4}$ level is expected since the emissions (illustrated by the isoprene emission curves in Fig. S2) in the new inventory are higher for most years compared to the constant year 2000 emissions in the old inventory. Larger emissions of components like isoprene and CO results in lower $\mathrm{OH}$ values and reduced $\mathrm{CH}_{4}$ loss. However, accounting for inter-annual variation of vegetation emissions of $\mathrm{CO}$ and NMVOCs does not shift the periods of growth and stagnation. Neither does it lead to larger year to year fluctuations in $\mathrm{CH}_{4}$ levels. Compared to surface measurements (discussed in section 3.2 of the main article) the underestimation of $\mathrm{CH}_{4}$ levels is less in the "bio" simulation, except from that there is no improvement in model performance. 


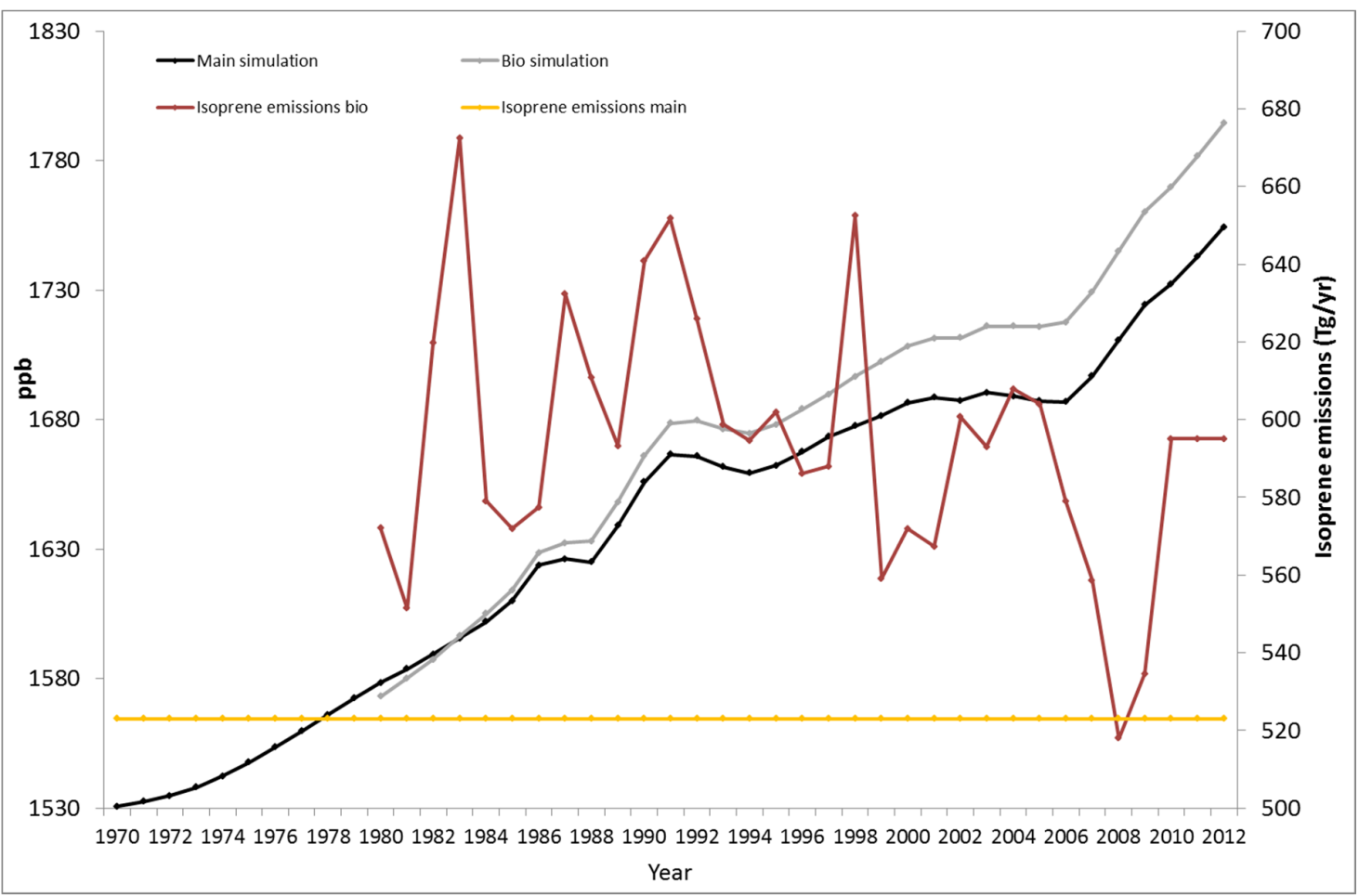

3 Figure S2. Surface $\mathrm{CH}_{4}$ levels and isoprene emissions in main simulation and bio simulation.

$5 \quad$ S5.2 Influence of financial crisis.

6 The period 2009-2012 was rerun with slightly different emissions evaluating whether the

7 recent financial crisis had any significant impact on $\mathrm{CH}_{4}$ levels. Here, the emissions from petroleum and solid fuel production and distribution were scaled with BP Statistical Review of World Energy (bp.com/statisticalreview) numbers for gas production, oil and coal consumption resulting in a drop in total emissions in 2009 (Error! Reference source not found. main article). However, the evolution in emissions from 2010 with this alternative extrapolation is rather similar to that for the standard extrapolation. Due to the drop in emissions in 2009 in the "financial" run methane loss after 2009 is lower than for the "main" simulation (Fig. S3). The emission growth in 2011 and 2012 is also slightly lower in the financial simulation. This results in declining methane loss for these years in the "financial" simulation. In contrast the methane loss in 2011 and 2012 is rather stable in the "main" simulation. Despite differences for the methane loss the methane burden is very similar in the two simulations. Therefore, it seems likely that the financial crisis had small impact on the methane burden, but due to the long methane lifetime some of the difference in methane loss could manifest as burden changes after 2012, which is the end-year of our simulations. 


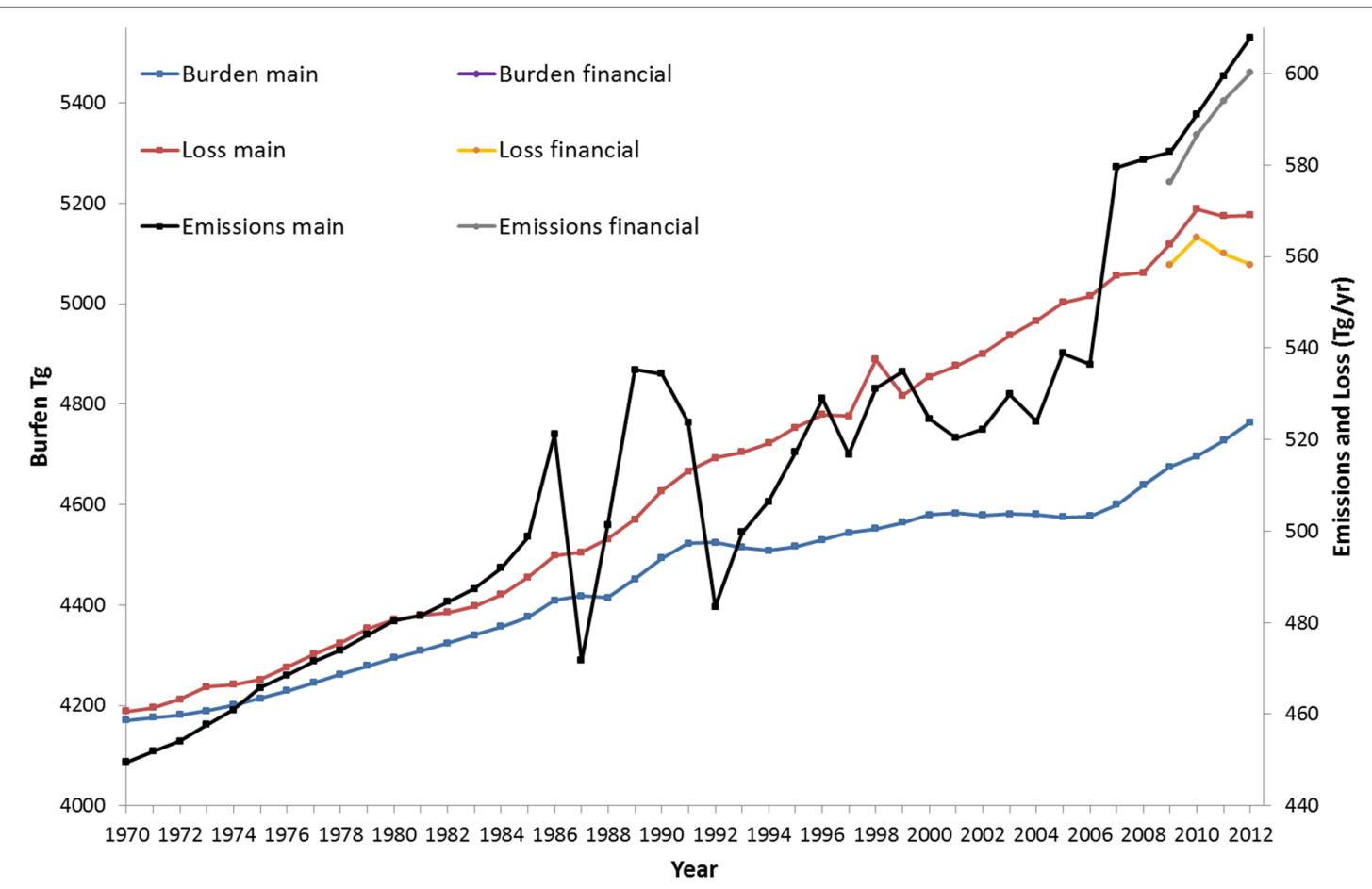

Figure S3. Methane budget in main and financial simulations.

\section{S6 Comparison with CO observations}

Since reaction with $\mathrm{OH}$ is the major loss of $\mathrm{CO}$ from the atmosphere a comparison with $\mathrm{CO}$ measurements indicates whether modelled changes of $\mathrm{OH}$ are realistic. In this section, a first elementary evaluation is made based on comparison between our model results and observation-based estimates of global mean surface CO levels (Fig. S4). There is very good agreement for the long term evolution (years-decades). The same is the case for short term (year to year) variations, especially after 1996 when our simulations include inter-annual variability in meteorology and biomass burning emissions (CO, NOx and NMVOCs). Our simulations do not fully account for the effect of the Pinatubo eruption and this also explains parts of the model discrepancy for the early nineties. Fig. S5 shows that the modeled gradual decline in CO levels over the period 1991-2012 is caused by stable to moderately declining $\mathrm{CO}$ emissions over the period combined with increasing $\mathrm{OH}$ for most of the period. Much of the large year to year fluctuations in CO levels (black line) are due to variation in emissions (purple line) caused by irregular occurrence and extent of vegetation fires. To summarize, the good agreement between our model and the observation based estimates supports that both the applied $\mathrm{CO}$ emission inventory and calculated $\mathrm{OH}$ changes are realistic. 
1 The WDCGG global mean estimate is higher than the NOAA ESRL (Fig. S4) since NOAA

2 ESRL is based on relatively unpolluted marine boundary layer stations while WDCGG

3 include inland stations in their calculations. $\mathrm{CO}$ is more unevenly mixed than $\mathrm{CH}_{4}$ due to its

4 shorter lifetime. How polluted versus un-polluted air masses go in the global mean

5 calculations therefore matters. The modeled global mean is based on all grid-boxes in the

6 lowest model layer and one reason for its higher value might be the above mentioned

7 sensitivity. However, comparing seasonal distributions (not shown) the model seems to

8 overestimate CO levels throughout the Northern Hemisphere summer season and that is likely

9 the main reason for its higher global mean.

10

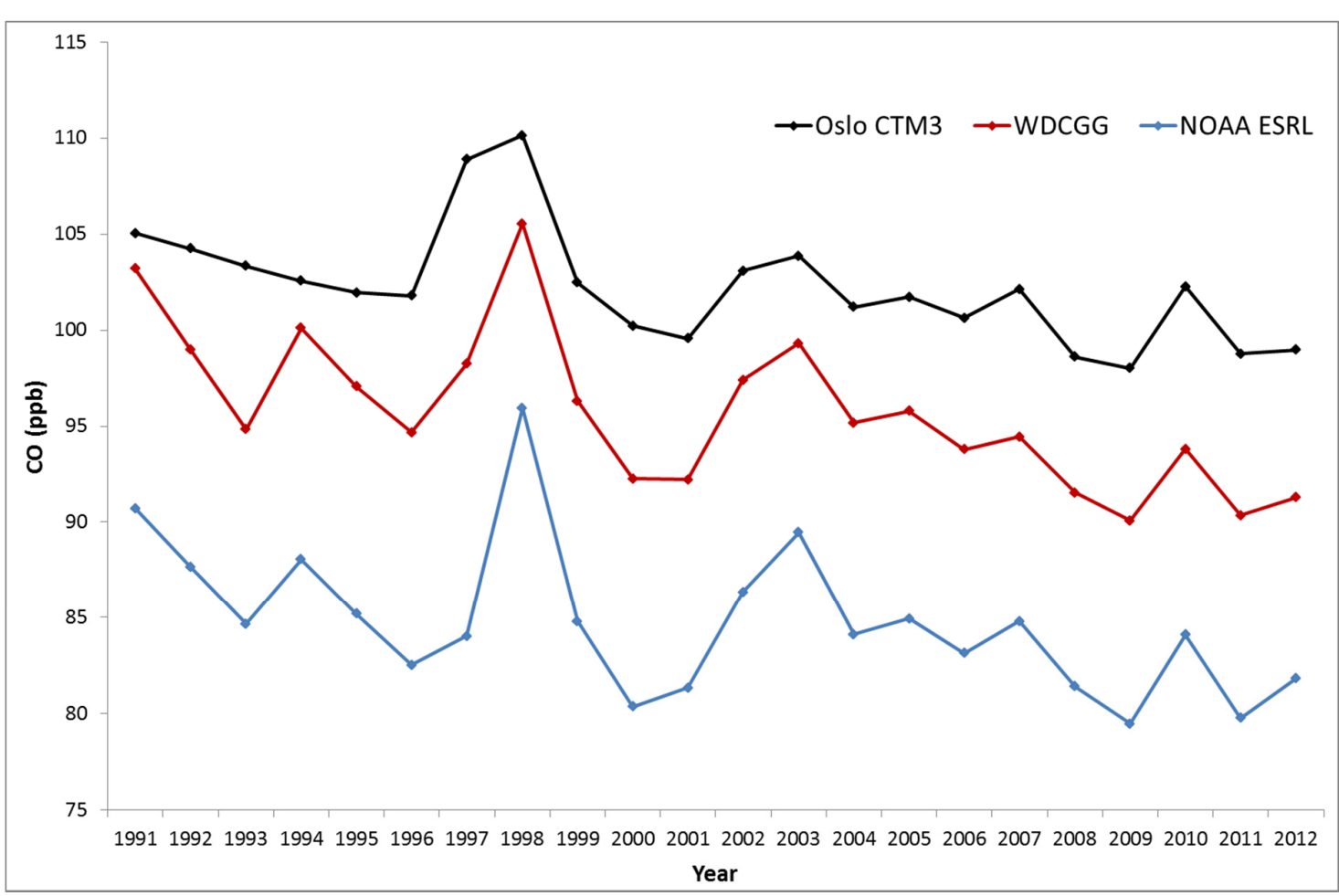

Figure S4. Comparison of model and observation based yearly global mean surface CO for the period 1991-2012. NOAA ESRL data set provided by Paul Novelli, personal communication. WDCGG data set (WMO/WDCGG/GAW (2015) provided by WDCGG, personal communication. 


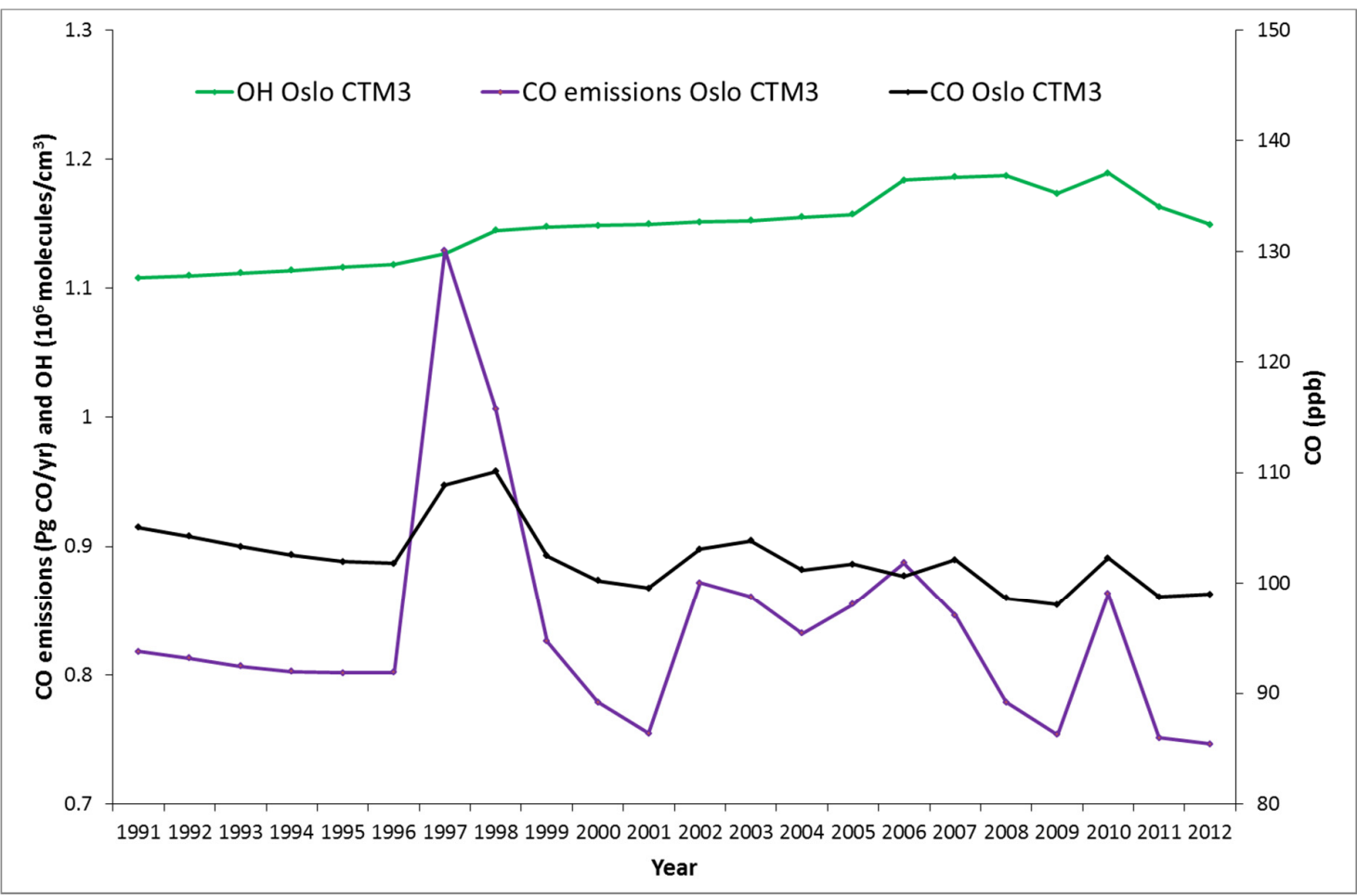

Figure S5. Yearly global average atmospheric $\mathrm{OH}$ concentration in the main simulation using the reaction rate with $\mathrm{CO}$ as averaging kernel and yearly total global $\mathrm{CO}$ emissions (left yaxis). Modeled global mean surface CO (right y-axis).

\section{Acknowledgements}

We thank WDCGG and Paul Novelli for providing and sharing CO datasets used in figure Figure S4.

\section{References}

Bousquet, P., Ringeval, B., Pison, I., Dlugokencky, E. J., Brunke, E. G., Carouge, C., Chevallier, F., Fortems-Cheiney, A., Frankenberg, C., Hauglustaine, D. A., Krummel, P. B., Langenfelds, R. L., Ramonet, M., Schmidt, M., Steele, L. P., Szopa, S., Yver, C., Viovy, N., and Ciais, P.: Source attribution of the changes in atmospheric methane for 2006-2008, Atmos. Chem. Phys., 11, 3689-3700, 10.5194/acp-11-3689-2011, 2011.

Guenther, A., Karl, T., Harley, P., Wiedinmyer, C., Palmer, P. I., and Geron, C.: Estimates of global terrestrial isoprene emissions using MEGAN (Model of Emissions of Gases and Aerosols from Nature), Atmos. Chem. Phys., 6, 3181-3210, 10.5194/acp-6-3181-2006, 2006. 
1 Holton, J. R.: An introduction to dynamic meteorology, 3er edition, Academic Press, San

2 Diego, USA, 1992

3 Holtslag, A. A. M., and Boville, B. A.: LOCAL VERSUS NONLOCAL BOUNDARY-

4 LAYER DIFFUSION IN A GLOBAL CLIMATE MODEL, Journal of Climate, 6, 1825-

5 1842, 10.1175/1520-0442(1993)006<1825:lvnbld >2.0.co;2, 1993.

6 Peixoto, J. P., and Oort, A. H.: Physics of climate, Springer-Verlag, New York, USA, 1992.

7 Seinfeld, J. H., and Pandis, S. N.: Atmospheric chemistry and physics: from air pollution to

8 climate change, John Wiley \& Sons, New York, USA, 1998

9 Sindelarova, K., Granier, C., Bouarar, I., Guenther, A., Tilmes, S., Stavrakou, T., Müller, J.

10 F., Kuhn, U., Stefani, P., and Knorr, W.: Global dataset of biogenic VOC emissions

11 calculated by the MEGAN model over the last 30 years, Atmos. Chem. Phys. Discuss., 14, 12 10725-10788, 10.5194/acpd-14-10725-2014, 2014.

13 WMO/WDCGG/GAW: Data Summary report, No.39, 2015. Available at

14 http://ds.data.jma.go.jp/gmd/wdcgg/pub/products/summary/sum39/sum39.pdf 